\title{
Intensive rehabilitation as an independent determinant of better outcome in patients with lung tumors treated by thoracic surgery
}

\author{
Oliwia Glogowska ${ }^{1}$, Maciej Glogowski², Sebastian Szmit ${ }^{3}$
}

\author{
${ }^{1}$ Department of Rehabilitation, The Maria Sklodowska-Curie Memorial Cancer Centre \\ and Institute of Oncology, Warsaw, Poland \\ ${ }^{2}$ Lung and Thoracic Tumors Department, The Maria Sklodowska-Curie Memorial \\ Cancer Centre and Institute of Oncology, Warsaw, Poland \\ ${ }^{3}$ Department of Pulmonary Circulation and Thromboembolic Diseases, Centre \\ of Postgraduate Medical Education, Otwock, Poland
}

Submitted: 24 June 2015

Accepted: 17 September 2015

Arch Med Sci 2017; 13, 6: 1442-1448

DOI: 10.5114/aoms.2016.60706

Copyright $\odot 2016$ Termedia \& Banach

\section{Abstract}

Introduction: The frequency of postoperative complications after thoracic surgery remains high. Rehabilitation may become a procedure characterized by a high cost-effectiveness ratio. The aim of the study was to determine the independent importance of intensive rehabilitation in patients with lung tumors treated by thoracic surgery.

Material and methods: The prospective observational study included two groups of patients: 187 patients treated according to the historical scheme including thoracic surgery without specific exercises improving cardio-pulmonary capacity, and 215 patients treated in agreement with the innovative algorithm of perioperative intensive physiotherapy until discharge from hospital. The evaluated clinical endpoints comprised bronchoscopy for pulmonary toilet and all other possible postoperative complications.

Results: The use of intensive physiotherapy significantly shortened the duration of hospitalization through reducing the frequencies of different postoperative complications. The specific clinical benefit was associated with a significantly lower rate of bronchoscopy performance for pulmonary toilet $(16 \%$ vs. $5.6 \%, p=0.0006)$. Multivariate regression analyses revealed intensive physiotherapy as a significant independent predictor for all postoperative complications ( $\mathrm{OR}=0.57 ; 95 \% \mathrm{Cl}: 0.323-0.988 ; p=0.045)$ and need to perform bronchoscopy for pulmonary toilet $(\mathrm{OR}=0.24 ; 95 \% \mathrm{Cl}$ : $0.11-0.51$; $p=0.0002$ ).

Conclusions: The study showed the strong independent positive effect of intensive rehabilitation in patients with lung tumors treated by thoracic surgery.

Key words: intensive rehabilitation, thoracic surgery, complications.

\section{Introduction}

Lung tumors seem to be the main causes of premature deaths [1]. They are responsible for patients' earlier disability and cardiopulmonary insufficiency. In this specific group of patients individually tailored training may significantly improve spirometric parameters, increase physical fitness and give a chance of safer radical surgical treatment with reduction of all costs [2, 3].

\author{
Corresponding author: \\ Sebastian Szmit \\ Department of Pulmonary \\ Circulation and \\ Thromboembolic Diseases \\ Centre of Postgraduate \\ Medical Education \\ 14/18 Borowska St \\ 05-400 Otwock, Poland \\ Phone: +48227103052 \\ E-mail: s.szmit@gmail.com
}


The role of physiotherapy in decreasing the number of postoperative complications in patients treated surgically for lung cancer and other thoracic neoplasms has not been well documented so far. The available publications show an insufficient level of evidence, the number of patients in treatment groups is small, and there are no prospective trials with randomization for particular interventions. The value of obtained observations is unequivocal due to the large number of various rehabilitation programs.

The main aim of the study was to evaluate the independent effect of intensive rehabilitation on the occurrence of postoperative complications and need to perform bronchoscopy for pulmonary toilet in patients with lung tumors treated by thoracic surgery.

\section{Material and methods}

The primary inclusion criterion for the study was surgical treatment for primary or secondary chest neoplasm conducted in the Lung and Thoracic Tumors Department, The Maria SklodowskaCurie Memorial Cancer Centre and Institute of Oncology. The study was performed in accordance with requirements of the local bioethical committee, and full informed consent was obtained from all patients before participating in the study.

The exclusion criteria comprised: (1) difficulties in interpretation of spirometry results: non-cooperative patients, measurement error, lack of repeatable and reliable expiration volume measurements; (2) lack of patient's informed consent to participate in the study; (3) inability to perform at least moderate exercises required during the rehabilitation program; (4) lack of typical signs of heart failure; (5) lack of typical signs of coronary artery disease; (6) history of symptomatic arrhythmias; (7) uncontrolled arterial hypertension; (8) obesity causing exercise intolerance defined as body mass index (BMI) $>30 \mathrm{~kg} / \mathrm{m}^{2}$; (9) uncontrolled diabetes mellitus; (10) symptomatic anemia or hemoglobin level below $10 \mathrm{~g} / \mathrm{dl}$; (11) history of asthma or abnormal peak expiratory flow values; (12) recognized GOLD 3 or 4 in classification of severity of airflow limitation in chronic obstructive pulmonary disease; (13) chronic respiratory failure; (14) history of pulmonary embolism.

The final analysis comprised 402 patients:

- group 1: 187 patients treated according to the historical scheme including thoracic surgery without specific exercises improving cardio-pulmonary capacity;

- group 2: 215 patients treated in agreement with the innovative algorithm of perioperative intensive physiotherapy continued until discharge from hospital.

Primary characteristics included: age, sex, type of thoracic surgery, history of lung operations in the past, and diagnostic spirometry result. There were no differences in the operative techniques, surgical instrumentarium or perioperative pharmacological prophylaxis between groups. The new proprietary program of patients' rehabilitation was introduced into the standard management in 2009. The details are presented in Table I. The program of rehabilitation was conducted in accordance with local ethical guidelines.

Primary clinical observation endpoints were: (1) postoperative complications or (2) necessity of bronchofiberoscopy (BFS) for pulmonary toilet during $72 \mathrm{~h}$ after thoracic surgery. In the authors' opinion these events determine the patients'

Table I. Proposed rehabilitation program

\begin{tabular}{|c|c|}
\hline $\begin{array}{l}\text { Preoperative } \\
\text { rehabilitation }\end{array}$ & $\begin{array}{l}\text { Education } \\
\text { Deep breathing exercises }\end{array}$ \\
\hline $\begin{array}{l}\text { First day after } \\
\text { surgery }\end{array}$ & $\begin{array}{l}\text { Vibration massage: } 5-10 \text { min twice a day } \\
\text { Deep breathing exercises: } 5 \text { in each series twice a day } \\
\text { Effective coughing exercises: } 5 \text { in each series twice a day } \\
\text { Upper-limb exercise training: } 5 \text { in each series twice a day } \\
\text { Lower-limb exercise training: } 5 \text { in each series twice a day } \\
\text { Controlled breathing training Triflo (respiratory exercise system for inspiration and expiration): } \\
10 \text { times inhale-exhale every } 0.5 \mathrm{~h} \text { for } 8 \mathrm{~h} \\
\text { Pionisation (getting up from lying to sitting and then to standing position): at least twice a day } \\
\text { Marching in place: } 50 \text { steps with high lifting knees, rest, next } 50 \text { steps } \\
\text { Anti-edematous prevention: } 5 \text { times the circulation feet and wrists (performing rotational } \\
\text { movements in the ankle and hip), } 5 \text { times bend and straighten ankle and elbow every } 0.5 \mathrm{~h} \text { for } 8 \mathrm{~h}\end{array}$ \\
\hline $\begin{array}{l}\text { From second day } \\
\text { after surgery } \\
\text { until the end of } \\
\text { hospitalization }\end{array}$ & $\begin{array}{l}\text { Continuation of the physiotherapy from the previous day } \\
\text { Walking down the hall: } 60 \mathrm{~m} \text {, plus every other day for } 60 \mathrm{~m} \text { more } \\
\text { Gymnastics group: } 15 \text { min every day } \\
\text { After removal of surgical drains: } \\
\text { - Training on the bike: } 10 \text { min twice a day } \\
\text { - Training on the stairs: entrance on the first floor } \\
\text { - Training on the Stairmaster: } 11 \text { times entrance to the stepper }\end{array}$ \\
\hline
\end{tabular}


prognosis. The secondary observation point was the length of the hospital stay, which reflects one of the possible costs.

The analysis of postoperative complications comprised:

(a) cardiovascular complications: supraventricular arrhythmias, development of clinical heart failure, sudden circulation arrest, myocardial infarction, development of arterial hypertension;

(b) surgical complications: pneumothorax, lack of lung expansion, prolonged drainage (> 7 days), wound dehiscence, need of re-thoracotomy, pulmonary abscess, respiratory insufficiency, chyle leak, re-insertion of drain;

(c) other complications: pneumonia, development of psychosis, bulbar syndrome, iatrogenic indigestion, necessity of parenteral nutrition.

Our center has the specific adopted principle that the patients remain in the intensive care unit during first $72 \mathrm{~h}$ after thoracic surgery. Therefore, all possible complications were observed under strict clinical supervision and the program of rehabilitation was implemented under adequate control (Table I).

The only indication for BFS was a necessity of aspiration of secretion from the bronchial tree. The rescue BFS was performed when a decrease of resting oxygen saturation below $90 \%$ and new radiological abnormalities in the lungs were observed with an increase of body temperature or number of leukocytes over the upper limits, which may have led to respiratory insufficiency. The analysis included only procedures conducted in the intensive care unit. Diagnostic BFS (for example performed to evaluate the condition of the bronchial stump) was not taken into account.

In the whole population of 402 patients the following clinical factors were analyzed: individually planned rehabilitation - whether conducted or not, sex, open thoracic surgery in the past, type of current thoracic operation (anatomical resection vs. other types of procedures), age, forced expiratory volume in $1 \mathrm{~s}\left(\mathrm{FEV}_{1}\right)<92 \%$ and forced vital capacity (FVC) $<96 \%$. The differentiating criterion for spirometric parameter values $\left(\mathrm{FEV}_{1}\right.$, FVC) was the median for the whole study population. Clinical characteristics of the patients were used to reveal the main factors determining the occurrence of primary observation points in both groups.

\section{Statistical analysis}

All analyses were conducted using the Statistica software. The normality of distribution of continuous variables was analyzed using the Shapiro-Wilk test. Non-normally distributed values were described as median and quartiles and compared by the non-parametric Mann-Whitney $U$ test. Nominal variables were described as frequency and compared using the $\chi^{2}$ test. Multivariate regression analysis was used to determine prognostic factors. A test $p$-value $\leq 0.05$ was regarded as statistically significant.

\section{Results}

The analysis of both groups of patients, historical and innovative with rehabilitation, did not show any differences apart from age; patients with implemented physiotherapy were significantly older (Table II).

Comparative analysis of the occurrence of primary observation points revealed that the number of BFS procedures was significantly lower in the group with implemented rehabilitation. There were no statistically significant differences in frequency of postoperative complications, but the absolute number of events was smaller in group 2 with rehabilitation (Table III). The analysis of the secondary observation point showed a significant difference and shorter median of hospital stay for patients who received rehabilitation (Table III).

The multivariate logistic regression analysis demonstrated a positive effect of the implemented rehabilitation model on the decrease of frequency of complications in patients operated for lung tumors (Table IV). Rehabilitation decreased the risk of all postoperative complications almost twofold, i.e. by $43 \%(\mathrm{OR}=0.57 ; 95 \% \mathrm{Cl}$ : 0.323-0.988; $p=0.045$ ). Independent negative predictive factors included anatomical resection (lobectomy, pneumonectomy), age and the value of $\mathrm{FEV}_{1}$. Anatomical resection increased the risk more than threefold $(\mathrm{OR}=3.07 ; 95 \% \mathrm{Cl}: 1.73-$ 5.44; $p=0.0001)$. A value of $\mathrm{FEV}_{1}$ below $92 \%$ increased the risk more than twofold $(O R=2.15$; 95\% Cl: $1.07-4.34 ; p=0.03)$, but each year of age increased the risk by $3 \%(\mathrm{OR}=1.03 ; 95 \% \mathrm{Cl}$ : 1.007-1.054; $p=0.01$ )

The multivariate logistic regression analysis for the necessity of BFS confirmed that the perioperative training decreased the risk of BFS after thoracic surgery (Table $\mathrm{V}$ ). Rehabilitation decreased the risk fourfold $(\mathrm{OR}=0.24 ; 95 \% \mathrm{Cl}$ : 0.11-0.51; $p=0.0002)$. Anatomical resection increased the risk almost fourfold $(\mathrm{OR}=3.72 ; 95 \% \mathrm{Cl}: 1.78-$ 7.78; $p=0.0005)$. A value of FVC below $96 \%$ increased the risk almost threefold $(\mathrm{OR}=2.85$; 95\% Cl: $1.18-6.91 ; p=0.02)$.

In the subgroup of 119 patients after anatomical lung resection, all possible postoperative complications were recognized more frequently in patients without rehabilitation $(41.2 \%$ vs. $23.5 \%$; $p=0.04)$, which was associated with significantly longer length of hospitalization (Table $\mathrm{VI}$ ). 
Table II. Clinical characteristics of patients included in the study

\begin{tabular}{|c|c|c|c|c|}
\hline Parameter & All $(N=402)$ & $\begin{array}{c}\text { Group 1 } \\
\text { (historical) } \\
n=187\end{array}$ & $\begin{array}{c}\text { Group 2 } \\
\text { (innovative) } \\
n=215\end{array}$ & $P$-value \\
\hline Age: & & & & 0.01 \\
\hline Median & 57.5 & 55 & 59 & \\
\hline Quartiles & $47-66$ & $43-64$ & $49-67$ & \\
\hline Gender: & & & & 0.69 \\
\hline Female & 187 & 85 & 102 & \\
\hline Male & 215 & 102 & 113 & \\
\hline History of thoracic surgery & $98(24.4 \%)$ & $47(25.1 \%)$ & $51(23.7 \%)$ & 0.74 \\
\hline Type of present lung resection: & & & & 0.34 \\
\hline $\begin{array}{l}\text { Anatomical lung resection } \\
\text { (pneumonectomy or lobectomy) }\end{array}$ & 119 & $\begin{array}{c}51 \\
(5 \times \text { pneumonectomy })\end{array}$ & $\begin{array}{c}68 \\
(7 \times \text { pneumonectomy })\end{array}$ & \\
\hline $\begin{array}{l}\text { Wedge resections } \\
\text { (metastasectomy, chest wall } \\
\text { resections, mediastinal tumors } \\
\text { resections) }\end{array}$ & 283 & 136 & 147 & \\
\hline $\mathrm{FEV}_{1} \%:$ & & & & 0.17 \\
\hline Median & 92 & 95 & 90 & \\
\hline Quartiles & $81-103$ & $83-101$ & $80-104$ & \\
\hline FVC\%: & & & & 0.46 \\
\hline Median & 96 & 96 & 98 & \\
\hline Quartiles & $85-106$ & $86-105$ & $85-107$ & \\
\hline
\end{tabular}

Table III. Prevalence of primary and secondary endpoints in both groups of patients

\begin{tabular}{|lccc|}
\hline Parameter & $\begin{array}{c}\text { Group 1 (historical) } \\
n=187\end{array}$ & $\begin{array}{c}\text { Group 2 (innovative) } \\
n=215\end{array}$ & $P$-value \\
\hline All complications* & $37(19.8 \%)$ & $32(14.9 \%)$ & 0.19 \\
\hline Cardiovascular & $11(5.9 \%)$ & $9(4.2 \%)$ & 0.44 \\
\hline Surgical & $24(12.8 \%)$ & $23(10.7 \%)$ & 0.51 \\
\hline Others & $8(4.3 \%)$ & $5(2.3 \%)$ & 0.41 \\
\hline BFS (bronchoscopy for pulmonary toilet) & $30(16 \%)$ & $12(5.6 \%)$ & 0.0006 \\
\hline Length of hospital stays [days] & $\begin{array}{c}\text { Median }=8 \\
\text { Quartiles: } 7-10\end{array}$ & $\begin{array}{c}\text { Median }=7 \\
\text { Quartiles: } 6-8\end{array}$ & 0.004 \\
\hline
\end{tabular}

*There were patients with more than one complication.

Table IV. Multivariate logistic regression analysis for the risk of all complications

\begin{tabular}{|lccc|}
\hline Risk factors & Odds ratio & $95 \% \mathrm{Cl}$ & $\boldsymbol{P}$-value \\
\hline Rehabilitation vs. standard historical management & 0.57 & $0.323-0.988$ & 0.045 \\
\hline Gender: women vs. men & 1.19 & $0.68-2.08$ & 0.54 \\
\hline History of thoracic surgery & 0.90 & $0.44-1.85$ & $1.73-5.44$ \\
\hline Type of present lung resection: anatomical vs. wedge & 3.07 & $1.007-1.054$ & 0.0001 \\
\hline Age (each year) & 1.03 & $1.07-4.34$ & 0.01 \\
\hline FEV $<92 \%$ & 2.15 & 1.03 & $0.52-2.06$ \\
\hline FVC $<96 \%$ & & 0.93 \\
\hline
\end{tabular}


Table V. Multivariate logistic regression analysis for the need to perform bronchoscopy for pulmonary toilet

\begin{tabular}{|lccc|}
\hline Risk factors & Odds ratio & $95 \% \mathrm{Cl}$ & $P$-value \\
\hline Rehabilitation vs. standard historical management & 0.24 & $0.11-0.51$ & 0.0002 \\
\hline Gender: women vs. men & 0.98 & $0.48-1.99$ & 0.96 \\
\hline History of thoracic surgery & 0.70 & $0.27-1.81$ & 0.47 \\
\hline Type of present lung resection: anatomical vs. wedge & 3.72 & $1.78-7.78$ & 0.0005 \\
\hline Age (each year) & 1.03 & $0.998-1.057$ & 0.07 \\
\hline FEV $<$ < $92 \%$ & 1.08 & $0.46-2.55$ & 0.86 \\
\hline FVC $<96 \%$ & 2.85 & $1.18-6.91$ & 0.02 \\
\hline
\end{tabular}

Table VI. Prevalence of primary and secondary endpoints in subgroups of 119 patients after anatomical lung resection

\begin{tabular}{|lccc|}
\hline Variable & $\begin{array}{c}\text { Historical } \\
(n=51)\end{array}$ & $\begin{array}{c}\text { Innovative } \\
(n=68)\end{array}$ & $P$-value \\
\hline All complications* & $21(41.2 \%)$ & $16(23.5 \%)$ & 0.04 \\
\hline Cardiovascular & $5(9.8 \%)$ & $6(8.8 \%)$ & 0.86 \\
\hline Surgical & $12(23.5 \%)$ & $11(16.2 \%)$ & 0.31 \\
\hline Others & $6(11.8 \%)$ & $1(1.5 \%)$ & 0.049 \\
\hline BFS (bronchoscopy for pulmonary toilet) & $13(25.5 \%)$ & $11(16.2 \%)$ & 0.21 \\
\hline Length of hospital stay [days] & $\begin{array}{c}\text { Median }=9 \\
\text { Quartiles: 8-12 }\end{array}$ & $\begin{array}{c}\text { Median }=7 \\
\text { Quartiles: 7-8 }\end{array}$ & 0.0017 \\
\hline
\end{tabular}

${ }^{\star}$ There were patients with more than one complication.

\section{Discussion}

The present study seems unique as it demonstrates significant independent clinical benefits from individually planned rehabilitation for patients with lung tumors treated by thoracic surgery. The implemented perioperative rehabilitation program had a significant impact on the decrease of hospital stay and decrease of all possible postoperative complications including rescue bronchoscopy for pulmonary toilet.

There are only four randomized studies evaluating the effect of pulmonary physiotherapy on the frequency of postoperative complications in lung cancer patients. The first study conducted a 4-week program of preoperative rehabilitation with randomization in a blinded manner [4]. For 18 weeks only 9 patients were enrolled. The final results did not show any differences between the study group and the control group. The second study included a week program based on 10 individual sessions with a physiotherapist. For 12 months 19 patients were included. In the group receiving rehabilitation, shorter hospital stay was noted $(p=0.058)$, as well as significantly shorter duration of pleural cavity drainage and a lower percentage of patients in whom drainage for more than 7 days was needed $(p<0.05)$, as compared with the control group [4]. Morano et al., however, conducted a study with randomization, including 24 patients [5]. Four weeks of training were implemented before surgery. In patients from the study group a significant increase in the total lung volume was noted (measured in liters and as a percentage) as well as improvement in the parameters of physical fitness measured in the six-minute walk test (6MWT). The authors observed shorter hospital stay $(p=0.04)$, shorter duration of thoracic drainage $(p=0.03)$ and fewer pulmonary incidents of postoperative complications $(p=0.01)$ in the group with an intensive rehabilitation program. In contrast, in a recent, similar study, Reeve et al. in a group of 76 patients did not observe any difference in the hospitalization time or number of postoperative complications [6].

Our study was conducted without randomization, but the number of included patients was sufficiently high (402 patients) to definitely confirm the preliminary clinical benefits of exercise rehabilitation in thoracic surgical oncology. This has created the background to organize new randomized controlled trials with easily repeatable exercise interventions and well-defined cost-effectiveness ratios.

\section{Importance of patients' age}

The patients enrolled later in our innovative group turned out to be significantly older than 
the corresponding subjects in the historical group. Many authors stress that the risk of perioperative complications increases with the age of patients [7-9]. In our study the comparison of events between groups (historical vs innovative) did not show any increase in postoperative complications, even though the group with implemented rehabilitation was significantly older. It suggests indirectly high efficacy of pulmonary physiotherapy even in the group of elderly patients, who are increasingly being considered for thoracic surgery. Our study confirms the strong independent association between the implementation of rehabilitation and the occurrence of different side effects in the postoperative period. We added each year of patients' age as an independent factor in our multivariate analyses. Rehabilitation remained a positive prognostic factor, which may decrease the risk of postoperative complications over twofold, irrespectively of the age of patients and even type of surgery and spirometry results (Table IV).

\section{Importance of rehabilitation \\ in the intensive care unit}

It should be stressed that our observations also include intensification of rehabilitation during the patient's stay $(72 \mathrm{~h})$ in the intensive care unit. There are very few literature reports with a similar design. Only Castro et al. suggest a strong correlation between the intensity of physiotherapy and frequency of respiratory complications and duration of stay in the intensive care unit [10]. More intensive physiotherapeutic care was implemented for $24 \mathrm{~h}$ in the study group, but only for $6 \mathrm{~h}$ a day in the control group. A total of 146 subjects were evaluated, and it was found that an increase in the intensity of rehabilitation led to a decrease in the frequency of complications and shorter hospital stay.

One of the most frequent respiratory complications observed after surgery for lung neoplasms is accumulation of secretions in the respiratory tract, which is connected with the trauma of the surgical procedure, and opioid medications given for pain relief. These drugs increase the density of the secretions in the lungs and decrease the ciliary reflex. Additional exacerbating factors include postoperative pain, drowsiness and reluctance to exercise. Our results seem to show a strong correlation between early mobilization of patients and frequency of accumulation of secretions in the lungs, because the introduction of the proprietary rehabilitation program decreased independently the risk of pulmonary toilet bronchoscopy over fourfold (Table V). The studies of other authors confirm the same tendency in the reduction of the risk of postoperative complications, but in none of them was the necessity of BFS evaluated.

\section{Implications for patients after anatomical lung resection}

Very interesting results were found in our subgroup of 119 patients after anatomical lung resection. The hospitalization stay was shortened through a significant decrease of cardiovascular, surgical and other complications (Table VI). The frequency of rescue BFS was only insignificantly lower in this specific population. This observation seems to be our key finding, because it is well known that in Europe the risk of mortality and morbidity is higher after anatomical lung resection [11]. Salati et al. observed a group of 1518 patients after pulmonary resection and found that the rate of postoperative complications was 30\% [12]. In this analysis lobectomies comprised $71 \%$, pneumonectomies $13 \%$ and wedge resections $16 \%$.

\section{Importance of pulmonary rehabilitation in cancer patients}

There is a strong need to define the role of rehabilitation in different groups of cancer patients including those with significant coexisting internal diseases. Our study may be the first step to plan a randomized controlled Polish multicenter trial in this specific scientific field.

Pulmonary rehabilitation is regarded as additional treatment in the management of patients with chronic obstructive pulmonary disease [1315] and other lung diseases [16], but there is not sufficient evidence for implementation of the discussed method in patients who undergo lung resection for thoracic neoplasms.

Only Mujovic et al. documented that preoperative pulmonary rehabilitation significantly improves clinical status of patients with chronic pulmonary diseases before non-small cell lung cancer resection [17]. The beneficial effect of rehabilitation was seen in spirometry parameters (i.e. increase of $\mathrm{FEV}_{1}$ by $374 \mathrm{ml}$ and increase of vital lung capacity by $407 \mathrm{ml}, p<0.001$ ) and physical fitness (i.e. increase of the distance in $6 \mathrm{MWT}$ by $56 \mathrm{~m}$, $p<0.001)$. Although the authors did not analyze the effect of this improvement on reduction of postoperative complications, such non-pharmacological treatment of lung cancer patients seems to be necessary when their functional capacity is weakest. It would allow radical thoracic surgery to be performed.

\section{Conflict of interest}

The authors declare no conflict of interest.

\section{References}

1. Pikala M, Maniecka-Bryla I. Years of life lost due to malignant neoplasms characterized by the highest mortality rate. Arch Med Sci 2014; 10: 999-1006. 
2. Bobbio A, Chetta A, Ampolinni L, et al. Preoperative pulmonary rehabilitation in patients undergoing lung resection for non-small cell lung cancer. Eur J Cardiothoracic Surg 2008; 33: 94-8.

3. Jones LW, Paddle CJ, Evens ND, et al. Effects of presurgical exercise training on cardiorespiratory fitness among patients undergoing thoracic surgery for malignant lung lesion. Cancer 2007; 110: 590-8.

4. Benzo R, Wigle D, Novotny P, et al. Preoperative pulmonary rehabilitation before lung cancer resection: results from two randomized studies. Lung Cancer 2011; 74: 441-5.

5. Morano MT, Araujo AS, Nascimento FB, et al. Preoperative pulmonary rehabilitation versus chest physical therapy In patients undergoing lung cancer resection: a pilot randomized controlled trial. Arch Phys Med Rehabil 2013; 94: 53-8.

6. Reeve JC, Nicol K, Stiller K, et al. Does physiotherapy reduce the incidence of postoperative pulmonary complications following pulmonary resection via open thoracotomy? A preliminary randomized single-blind clinical trial. Eur J Cardiothorac Surg 2010; 37: 1158-67.

7. Mery CM, Pappas AN, Bueno R, et al. Similar long-term survival of elderly patients with non-small cell lung cancer treated with lobectomy or wedge resection within the surveillance, epidemiology and results database. Chest 2005; 128: 237-45.

8. Ginsberg RJ, Hill LD, Eagan RT, et al. Modern thirty-day operative mortality for surgical resection in lung cancer. J Thorac Cardiovasc Surg 1983; 86: 654-8.

9. Harpole DH, Decamp MM, Daley J. Prognostic models of thirty-day mortality and morbidity after major pulmonary resection. J Thorac Surg 1999; 117: 969-79.

10. Castro AM, Calil SR, Freitas SA, et al. Chest physiotherapy effectiveness to reduce hospitalization and mechanical ventilation length of stay in ICU patients. Respir Med 2013; 107: 68-74.

11. Varela G, Nuowa NM, Agostini P, et al. Chest physiotherapy in lung resection patients: state of the art. Semin Thoracic Surg 2011; 23: 297-306.

12. Salati $M$, Refai $M$, Pompilli $C$, et al. Major morbity after lung resection: a comparison between the European Society of Thoracic Surgeons Database system and the thoracic morbity and mortality system. J Thorac Dis 2013; 5: 217-22.

13. Lacasse Y, Wong E, Guayatt GH, et al. Metaanalysis of respiratory rehabilitation in chronic obstructive pulmonary disease. Lancet 1996; 348: 1115-9.

14. Bartels MN, Kim H, Whiteson JH, et al. Pulmonary rehabilitation in patients undergoing lung-volume reduction surgery. Arch Phys Rehabil 2006; 87 (suppl 1): 84-8.

15. Pierzchała W, Barczyk A, Górecka D, et al. Recommendations of Polish Society of Lung Diseases about diagnosis and therapy of chronic obstructive pulmonary disease (COPD). Pneumonol Alergol Pol 2010; 78: 318-47.

16. Mandal P, Sidhu MK, Kope, et al. A pilot study of pulmonary rehabilitation and chest physiotherapy versus chest physiotherapy alone in bronchiectasis. Respir Med 2012; 106: 1647-54.

17. Mujovic N, Mujovic N, Subotic D, et al. Preoperative pulmonary rehabilitation in patients with non-small cell lung cancer and chronic obstructive pulmonary disease. Arch Med Sci 2014; 10: 68-75. 